IEEE

COMMUNICATIONS

ISURVEYS

The Electronic Magazine of

Original Peer-Reviewed Survey Articles

www.comsoc.org/pubs/surveys

\title{
A SURVEY OF \\ HANDOVER ALGORITHMS IN DVB-H
}

\author{
XIAODONG YANG, GOETTINGEN UNIVERSITY \\ JANI VÄRE, NOKIA CORPORATION \\ THOMAS J. OWENS, BRUNEL UNIVERSITY
}

\begin{abstract}
Digital Video Broadcasting for Handhelds (DVB-H) is a standard for broadcasting IP Datacast (IPDC) services to mobile handheld terminals. Based on the DVB-T standard, DVB-H adds new features such as time slicing, MPE-FEC, in-depth interleavers, mandatory cell id identifier, optional 4K-modulation mode and the use of $5 \mathrm{MHz}$ bandwidth in addition to the usually used 6,7 , or $8 \mathrm{MHz}$ raster. IPDC over DVB-H is proposed for ETSI to complement the DVB-H standard by combining IPDC and DVB-H in an end-to-end system. Handover in such unidirectional broadcasting networks is a novel issue. In the last few years since the birth of DVB-H technology, great attention has been given to the performance analysis of DVB-H mobile terminals. Handover is one of the main research topics for DVB-H in mobile scenarios. Better reception quality and greater power efficiency are considered to be the main targets of handover research for DVB-H. New algorithms for different handover stages in DVB-H have been the subject of recent research and are currently being studied. Further novel algorithms need to be designed to improve the mobile reception quality. This article provides a comprehensive survey of the handover algorithms in DVB-H. A systematic evaluation and categorization approach is proposed based on the problems the algorithms solve and the handover stages being focused on. Criteria are proposed and analyzed to facilitate designing better handover algorithms for DVB-H that have been identified from the research conducted by the authors.
\end{abstract}

$\mathrm{D}$

igital Video Broadcasting - Terrestrial (DVB-T) was not only designed for transmitting TV-like video contents but also for transmitting data services [1-3]. Digital Video Broadcasting - Handheld (DVB-H) [4-6], formerly known as "DVB- $X$ " [7], is a unidirectional communication technology based on DVB-T. DVB-H and DVB-T were developed by the organization called DVB Project [8]. Recently, the DVB ad-hoc group Convergence of Broadcast and Mobile Services (CBMS) developed IPDC (IP Datacast) [9] over the DVB-H standard [10], which is currently being processed by the European Telecommunications Standards Institute (ETSI). The IPDC over DVB-H standard complements the DVB-H standard by defining OSI layers 3-7 and refining some of the OSI layer 2 specific protocols, especially Program Specific Information (PSI) and Service Information (SI).
DVB-H poses novel challenges for handover research. Before talking about the origin of the handover issues in DVB-H it is necessary to take a look at the services that are transmitted in DVB-H networks. The service contents in DVB-H networks are delivered in the form of IP datagrams using IP-based mechanisms or in the form of other network layer datagrams encapsulated into Multi-Protocol Encapsulation (MPE) sections [11]. This kind of service is called IPDC. Although IPDC services can be offered via existing GPRS or UMTS cellular networks by Multimedia Broadcast/Multicast Service (MBMS) [12-14], MBMS is only suitable for light traffic services such as short video clips. For heavy-duty streaming services, DVB$\mathrm{H}$ is a better solution because of its higher bit rate compared with that of MBMS. [15]. IPDC brings new characteristics for DVB-H networks. The benefits are as follows [16]: 


\begin{tabular}{|c|c|c|c|}
\hline Application layer & $\begin{array}{c}\text { Real time } \\
\text { content }\end{array}$ & $\begin{array}{c}\text { File based } \\
\text { content }\end{array}$ & ESG \\
\hline Presentation layer & $\begin{array}{c}\text { Source coding } \\
\text { H.264(Mpeg4) }\end{array}$ & $\begin{array}{c}\text { Source coding } \\
\text { H.264(Mpeg4) }\end{array}$ & $\begin{array}{c}\text { Coding } \\
\text { encapsulation } \\
\text { (XML) }\end{array}$ \\
\hline Session layer & RTP & FLUTE/ALC \\
\hline Transport layer & \multicolumn{3}{|c|}{ IP (IPv4/IPv6) } \\
\hline Network layer & \multicolumn{3}{|c|}{ MPE (MPE-FEC/Time Slicing) } \\
\hline Data link layer & \multicolumn{3}{|c|}{ DVB-T (4K mode, in-depth interleaver) } \\
\hline Physical layer & TPS & \\
\hline
\end{tabular}

Figure 1. DVB-H protocol stack.

- IPDC provides a platform for true convergence of services between DVB-H and cellular telecommunication networks (GPRS/UMTS).

- IPDC allows the coding to be decoupled from the transport layer, thus opening the door to a number of features benefiting handheld mobile terminals, including a variety of encoding methods which only require low power from a decoder (decoding high-bandwidth MPEG-2 encoded streaming video/audio is relatively power consuming).

- IPDC is relatively insensitive to any buffering or delays within the transmission (unlike MPEG-2).

- IPDC is well-suited for time-sliced transmission.

In a word, an IPDC service is suitable for handover in DVB-H.

But what are the advantages of mobile reception of DVB$\mathrm{H}$ compared to that of DVB-T?

VALIDATE [17] and MOTIVATE [18] were two European projects that addressed the issues of mobile reception of DVB-T signals [19]. Laboratory tests and field trials have shown that mobile applications of DVB-T are feasible using the code rate equals $1 / 2$ modes of the specification [20]. However, the tests of receivers also showed the limits of performance achievable for mobile television using DVB-T without enhancements to the receivers [21]. In addition, the power consumption of mobile reception of DVB-T is a big issue for battery powered terminals [22, 23].

DVB-H is the technique that was rolled out for the mobile portable reception of IPDC contents [24, 25]. Similar standards are used in Japan and Korea for mobile data broadcasting $[26,27]$. The scenario of single-frequency DVB-H networks consists of high-power DVB-H transmitters like those of DVB-T. However, multifrequency networks comprised of low power DVB-H transmitters are also expected to be a typical network scenario for DVB-H. With decreasing cell size, handover in DVB-H becomes a critical issue.

Handover in traditional cellular telecommunications networks (like GSM) refers to the mechanism that transfers an ongoing call from one cell to another as a user moves through the coverage area of the cellular system [28] and has long been a research topic. However, handover in DVB-H refers to the switching of the reception of IP-based services from one transport stream to another when the terminal moves through the coverage area of a DVB-H network [29]. In this survey the two different terms "channel" and "transport stream" are used for the same meaning. They both mean the path along which a communications signal is transmitted.

Soft handover is usually used to mean that radio links are added and removed in such a way that the device always keeps at least one radio link to the base station [30]. In DVB$\mathrm{H}$, this means that the received frequency and/or transport stream is changed without interruption of the ongoing reception.

It is considered important for researchers in the DVB-H area to understand the importance of handover, especially in multifrequency DVB-H networks. Therefore, this article provides a comprehensive survey of various aspects of the handover algorithms in DVB-H networks.

The article is structured as follows. We describe the technical features of DVB-H. Then a detailed introduction to handover in DVB-H is given and the differences between handover in DVB-H, DVB-T and cellular telecommunications networks are presented. Next, the authors' approaches to handover research in DVB-H are described with the handover challenges and handover stages followed. The different handover algorithms currently available are investigated. The authors' view of how to design a handover algorithm for DVB-H is presented. Finally, the article closes with the conclusions and a discussion of the projects related to and the research trends in handover algorithms in DVB-H networks.

\section{TECHNiCAL FeATURES OF DVB-H}

Time slicing, MPE-FEC, 4K mode, in-depth interleavers, DVB-H signaling (including the mandatory cell id identifier), and the use of $5 \mathrm{MHz}$ bandwidth are the essential elements that are introduced in DVB-H [29]. These features are located in the data link layer and the physical layer of the DVB-H protocol stack. Time slicing (in the data link layer) and DVB$\mathrm{H}$ signaling (in the data link layer and the physical layer) are the two features that are directly related to DVB-H handover.

\section{Protocol Stack}

The DVB-H protocol stack is shown in Fig. 1. The newly introduced DVB-H technical features are in the data link layer and the physical layer. The application services may be sent via Real Time Protocol (RTP) [31] for real time content (for example a TV program). Non-real-time data may be sent via a File Delivery Over Unidirectional Transport/Asynchronous Layered Coding (FLUTE/ALC) [32] data carousel (for example for file downloads). The Electronic Service Guide (ESG) is also broadcast using FLUTE/ALC. The handover issue in DVB-H is mainly an issue for the data link layer and the physical layer. An analysis and simulation of DVB-H link layer is done using finite-state Markov models in [33].

\section{TIME SLICING}

Time slicing is used in DVB-H to transmit data in periodic 


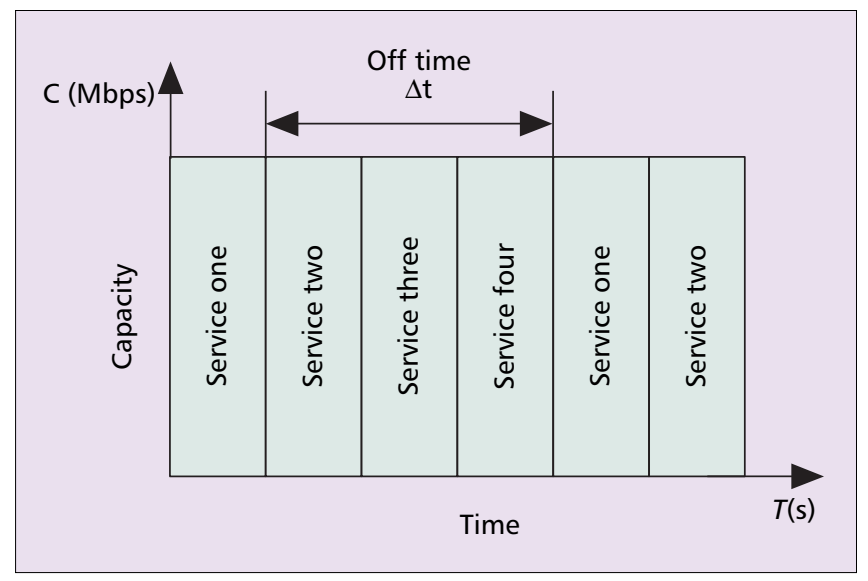

Figure 2. Time slicing illustration.

bursts. For a single service, the burst bit rates are significantly higher compared with that of DVB-T. Time slicing enables the tuner in a receiver to stay active only a fraction of the time while receiving bursts of a requested service; this saves battery power. It is claimed that up to 95 percent power saving can be achieved as compared with conventional and continuously operating DVB-T tuners [11]. The high-bit-rate signals will be buffered in the receiver memory. A brief performance analysis of the time slicing scheme in DVB-H is done by simulation in [34]. Time slicing offers, as an extra benefit, the possibility to use the same front-end to monitor neighboring cells between bursts, thus making seamless soft handover possible. May [35] showed how the off times between the transmissions bursts can be used to perform handovers, how they have to be synchronized, and what boundary conditions exist. A technology called "phase shifting" is proposed as a solution. Time slicing is illustrated in Fig. 2.

It is possible to use a combination of DVB-H (time sliced) and DVB-T (not time sliced) services in a single multiplex, as shown in Fig. 3 [36]. However, the power saving is decreased in this case due to a smaller data rate being available for time sliced services [36].

Another benefit of time slicing in DVB-H is that it is unique in terms of the power saving achieved. This means that the amount of power savings achieved by time slicing in DVB$\mathrm{H}$ could not be obtained when time slicing is used in DAB or DMB [37].

Depending on the transmission bit rate, burst size and burst duration, the off time $\Delta t$ in the transmission stream can vary [38]. According to [16], the burst parameters are shown in Fig. 4 and the formulas used to calculate the length of a burst, the off time and the achieved saving in power consumption are shown in Fig. 5. The DVB-H receiver can use this off time to synchronize and initialize soft handover to another cell that would be impossible without the use of time slicing.

\section{MPE-FEC}

Multi-Protocol Encapsulation (MPE) is a method to transmit IP data over DVB networks [39]. It specifies the carriage of IP packets within MPEG Private Data sections. The mobile reception of DVB-H is characterized by non-line-of-sight, multipath, Doppler impairments, strong propagation loss (especially for indoor reception), poor receiving antenna gain [40], and mobile channel interferences from adjacent TV and GSM channels and environmental factors such as weather and traffic. As a result, accessing a downstream high-bit-rate service with a handheld terminal is very demanding. The objective of the MPE Forward Error Correction (MPE-FEC) is to improve the Carrier/Noise $(\mathrm{C} / \mathrm{N})$ ratio and Doppler tolerance

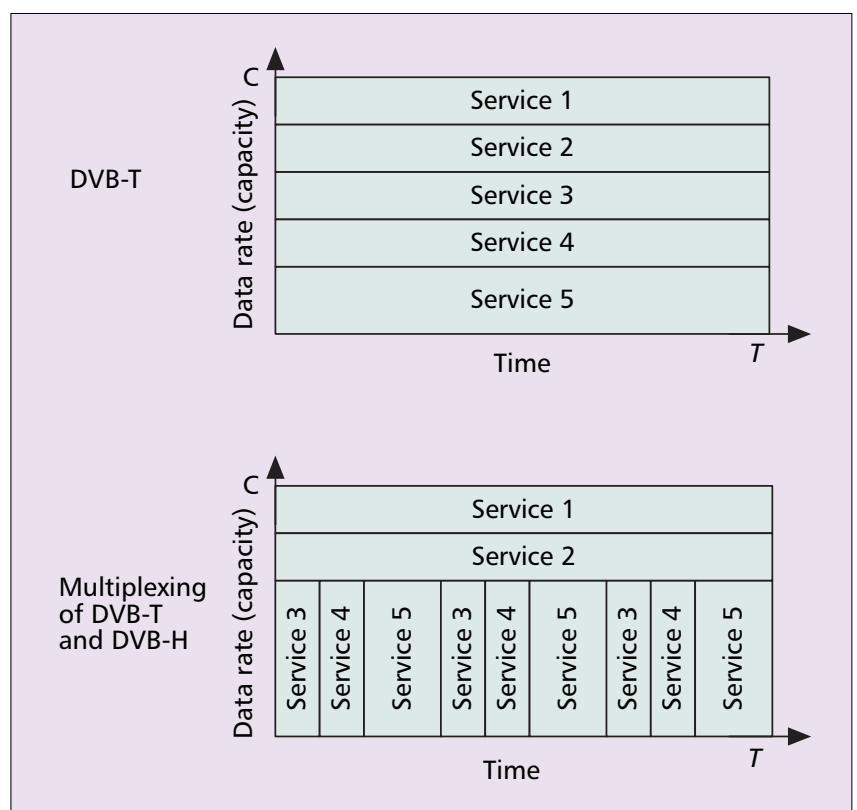

Figure 3. $D V B-T$ and multiplexing of $D V B-T$ and $D V B-H$.

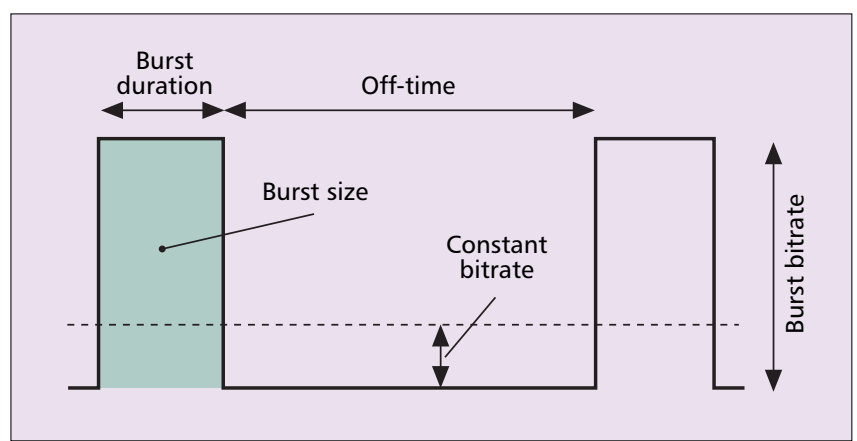

Figure 4. Time slicing burst parameters [16].

in mobile channels and to improve the tolerance to impulse interference [29]. However, MPE-FEC only works within individual time slices [41] and the size of one burst exactly corresponds to the content of one MPE-FEC frame [4]. Consequently, if a single transmission error cannot be corrected, the service drops out not only for the duration of the burst but also during the time up until the next burst is received.

\section{K MODE AND IN-DEPTH INTERLEAVERS}

The $4 \mathrm{~K}$ mode and the in-depth interleavers affect the physical layer of DVB-H, but do not affect the soft handover directly. However, their objectives are to improve Single Frequency Network (SFN) planning flexibility and to protect against short noise impulses caused by, for example, ignition interference and interference from various electrical appliances [29, 42]. In this case, they affect the mobile reception of DVB-H signals. The $4 \mathrm{~K}$ mode offers a trade off between mobility and SFN size in the network planning [29]. Since DVB-T does not include this mode, it is an option only in dedicated DVB-H networks [4]. For the $2 \mathrm{~K}$ and $4 \mathrm{~K}$ modes, the in-depth interleaver increases the flexibility of the symbol interleaving by decoupling the choice of the inner interleaver from the transmission mode [16, 29].

\section{DVB-H SIGNALING}

The objective of DVB-H signaling is to provide robust and 


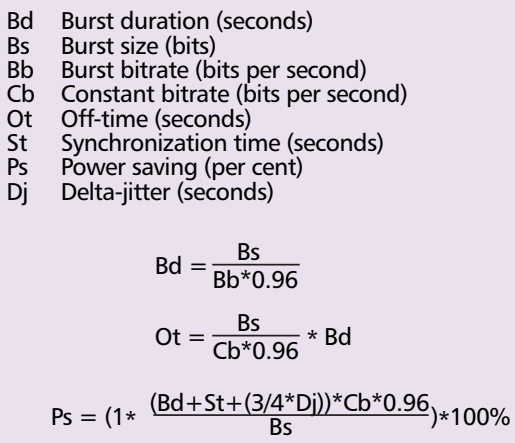

Figure 5. Formulas to calculate the length of a burst, off time and the achieved saving on power consumption [16].

easy-to-access signaling to DVB-H receivers, thus enhancing and speeding up service discovery [29]. It should be noted that DVB-H is based on DVB-T and most of the DVB-H specifications in the physical layers are the same as those of DVB-T which can be found in [43]. Besides the specifications in common with DVB-T, DVB-H has unique physical specifications. Only the DVB-H signaling used for handover is considered in this section. (The signaling bits specified for DVB-H but not used directly for handover will not be discussed.) There are two kinds of signaling information the DVB-H receiver can use. One is Transmission Parameter Signaling (TPS) signaling bits in the physical layer. The other is DVB-H specific signaling within Program Specific Information (PSI)/Service Information (SI) $[39,44,45]$. PSI/SI is the core signaling for enabling service discovery within DVB-T and also within other DVB systems. Since the PSI/SI used within DVB-H is different to that of other DVB systems, a subset of PSI/SI for IPDC over DVB-H is defined in [46]. The PSI/SI data enables a DVB-H receiver to discover IPDC over DVB-H specific services in the transport stream and also provides essential information for enabling handover.

The TPS is defined over 68 consecutive OFDM symbols, referred to as one OFDM frame. Each OFDM symbol conveys one TPS bit, so each TPS block contains 68 bits [43]. The TPS bits are located within the physical layer [42] so the signal for synchronization in the handover process is first obtained by utilizing the information contained in the TPS bits [47].

The Synchronization Word bits aid the receiver in synchronizing with the target frequency. The Cell Identifier conveys unique cell identification information to the receiver. The PSI/SI provides information on the DVB-H services carried by the different transport streams. Handover-related information in the PSI/SI is mainly contained in the Network Information Table (NIT), Program Association Table (PAT), Program Map Table (PMT) [44], and IP/MAC Notification Table (INT) [39].

\section{$5 \mathrm{MHZ}$ BANDWIDTH}

DVB-T standards use the 6,7 , or $8 \mathrm{MHz}$ raster in the frequency spectrum (namely, UHF and VHF). The introduction of $5 \mathrm{MHz}$ bandwidth into DVB-H provides new possibilities for using frequency spectrum other than that allocated to traditional broadcast use, for example, in the L band, which creates new challenges in terms of receiver design and also provides benefits in terms of system performance such as tolerance to Doppler shift in a mobile environment [16].

\section{HANDOVER IN DVB-H}

This section gives an overview of DVB-H handover and points out the key enablers that are needed for accomplishing DVB$\mathrm{H}$ handover by means of currently available standard methods. The aim is to give an overview of the handover principle that applies to all network configurations and hence the less efficient methods have been left out. A more extensive description of DVB-H handover, including the less efficient methods, is presented in [48].

Even though DVB-H was designed to be backwards compatible with DVB-T, there are differences between handover in DVB-T and handover in DVB-H. In addition to the use of time slicing and the resulting off-periods in DVB-H, another fundamental difference is in the signaling. Regardless of the fact that DVB-T and DVB-H share some PSI/SI tables, such as the NIT, PAT, PMT, INT and Time and Date Table (TDT), the DVB-H receiver does not need to support the Service Description Table (SDT) and Event Information Table (EIT). In [46], the SDT and EIT tables are considered mandatory for an IPDC over DVB-H network but optional for the receiver. Also, the linkage modes to enable support for handover to associated services, as defined in [45], are not supported in [46] and hence are not discussed within this section.

In DVB-T, a service is identified by a service id within the SDT and EIT. The EIT provides schedule information for the services advertised within the SDT. The PAT and PMT are used for associating services with elementary streams.

The identification of a service and the use of a service id in DVB-H are rather different to that of DVB-T. In DVB-H, the services are first mapped to IP addresses within the Electronic Service Guide (ESG) [49]. Next, the IP addresses are further mapped to service ids within the INT, where it is possible to associate all the $\overline{\mathrm{DV}} \mathrm{B}-\mathrm{H}$ services of an IP platform with only one service id. The discrimination between different DVB-H services within one service id, that is, association of elementary streams with IP streams, is done within the PMT by means of a combination of component_tag and service_id. Hence, within DVB-H, the service id is just another parameter in the mapping of IP addresses to elementary streams.

The handover in DVB-H, as defined in [16], occurs when the receiver receiving a transport stream switches to another transport stream and continues the reception of the previously received IP streams. According to this definition, DVB-H handover can occur only within MFN networks, between two different SFN areas that are part of the same network and between two different networks. In other words, handover in DVB-H occurs each time the received transport stream and/or frequency changes. To be able to operate in such a situation, the receiver needs to regularly monitor adjacent cells that have currently consumed IP streams available. This monitoring can be done by means of the NIT and INT.

The less dynamic information is carried within the NIT, which maps each transport stream with one cell_id, one or more frequencies, and optionally with the transposer frequency and subcell_id. Also, the geographical coordinates of the cells and possible subcells are signaled within the NIT.

The level of invariability of the INT depends on the network implementation. Each INT may announce association of IP streams within all the transport streams of the network or just within the transport streams available within neighboring cells. In the case of an MFN, network capacity can be saved if each INT announces only the association of the IP streams available within the neighboring cells. From the receiver perspective this means that receiver needs to update INT each time after handover.

For the handover between two different DVB-H networks, the same procedures are followed as described above, except that the other NIT, that is, NIT other, is needed for each network that is supported in addition to the current network. 


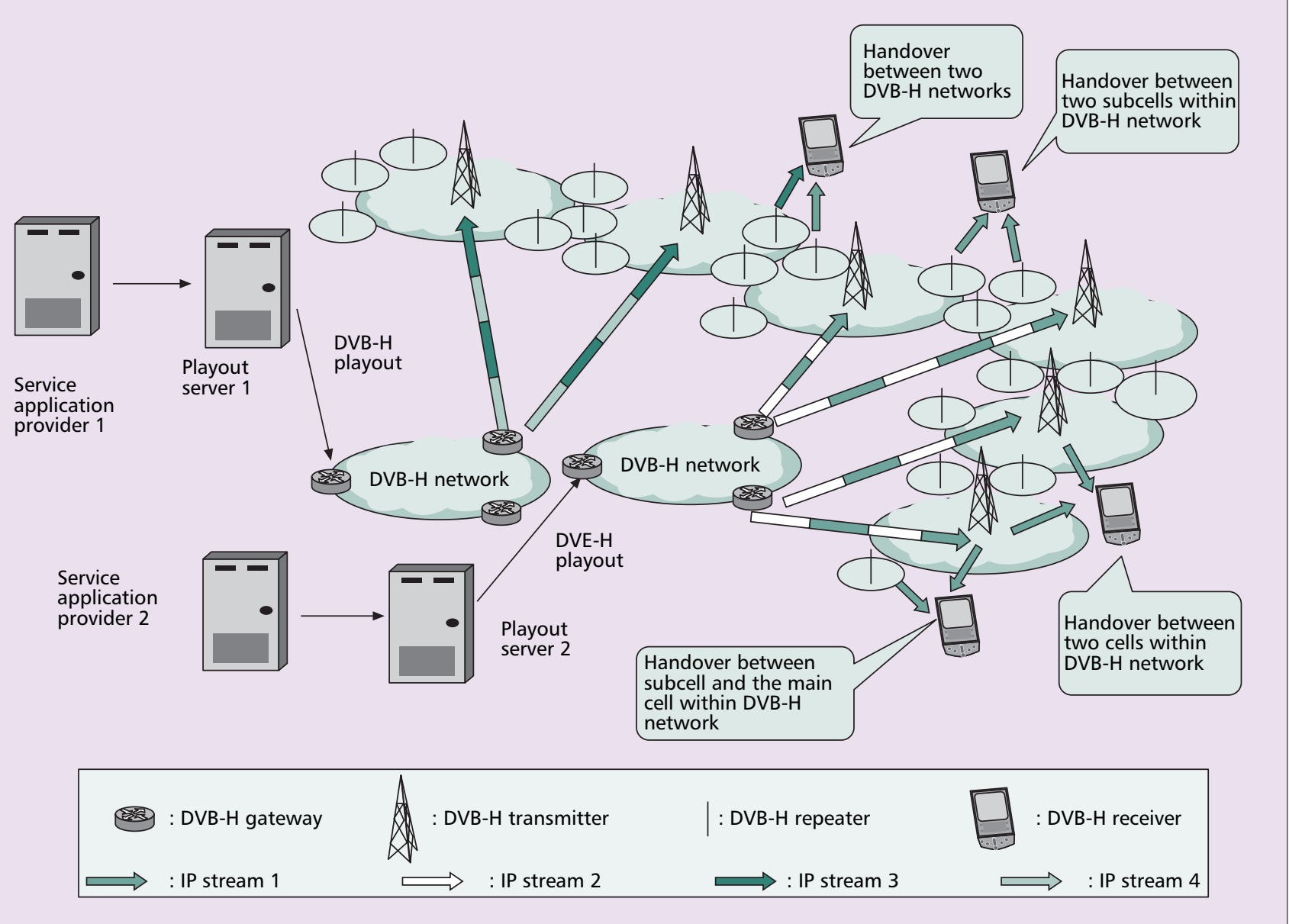

Figure 6. General handover situations in DVB-H networks.

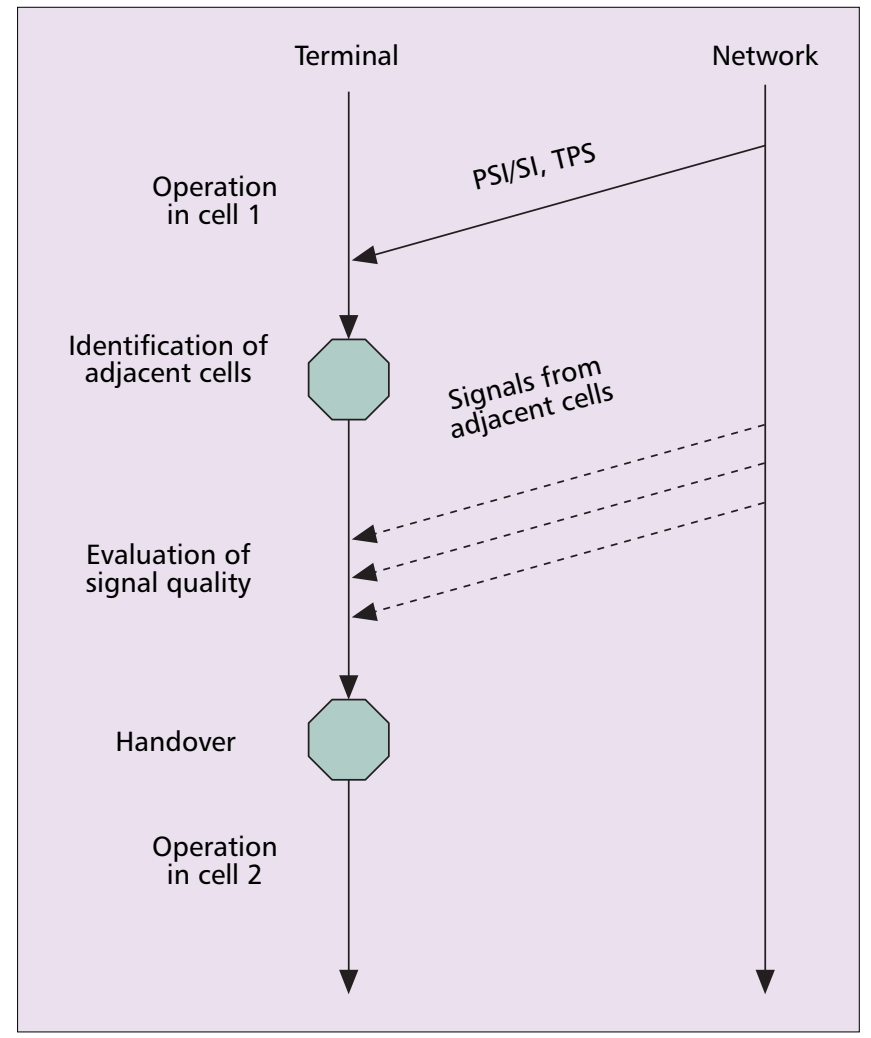

Figure 7. Passive handover according to [36].
Figure 6 shows the DVB-H handover schemes discussed above: handover between two DVB-H networks, handover between two subcells within a DVB-H network, handover between two cells within a DVB-H network, and handover between a subcell and the main cell within a DVB-H network.

It is expected that a DVB-H cell will usually be smaller than a DVB-T cell because of a low-gain receiver antenna, the low height of a transmitter antenna, building penetration losses, and fast fading in a mobile environment [40]. Thus, lowpower transmitters serving a network operating in a multifrequency network (MFN) mode, in networks composed of one or more Single Frequency Network (SFN) areas or a mixture of these two topologies, are the main network structure types for DVB-H. One of the main factors that affect the selection of the network topology is the need for localized services. Depending on the density of the localized services, the network topology can vary from a MFN composed of single transmitter cells to networks composed of one or more SFN areas. If localized services are not supported at all within the network, the whole network can consist of a single SFN area where handover is not needed. All other network types, except the network type covered exclusively with one SFN area, result in handovers. The handover frequency is dependent on the size of the cells, terminal mobility, and environmental factors (such as rural or urban), which are similar to the handover frequency factors in UMTS/GSM and so forth.

The handover in DVB-H has unique features compared with that of cellular telecommunications networks (e.g., UMTS) such as its unidirectional nature, being mobile initiated, time slicing being utilized, and always being soft handover. Taking UMTS as an example, the base station will communi- 
cate with the mobile terminal in the handover procedure and the availability of an interaction channel between the network and the terminal is essential for the successful completion of the handover [50]. On the other hand, DVB-H networks have no information as to who is using their services at a given time and where the terminal is possibly going to perform handovers. Since the DVB-H transmitter cannot obtain information from the DVB-H terminals, the DVB-H terminals themselves based on their own decisions must perform the handover.

Although some convergence terminals have both DVB-H and telecommunication capabilities, it is not always possible for a terminal to get in contact with the network to perform handover. Handover without an interaction channel in DVB-H is called passive handover while handover in DVB-H utilizing an interaction channel such as a UMTS return channel is called active handover [51]. Illustrations of these two kinds of handovers are given in Figs. 7 and 8 [36]. Since DVB-H does not require a mandatory return channel, in this survey only passive handover in DVB-H terminals is considered where the terminal has no interaction channel with the network infrastructures.

Soft handover is not possible for single antenna DVB-T terminals [36], because single antenna DVB-T terminals cannot make seamless handover without interruption of the continuing service. On the other hand, DVB-H terminals can make seamless handover (soft handover) because of its timeslicing transmission nature. The DVB-H standard brings the possibility of soft handover for single antenna terminals. There are two main features that make soft handover possible in the DVB-H standard, one is time slicing and the other one is the mandatory cell id identifier [29]. Time slicing creates off times that can be used for the monitoring of the adjacent cells without interruption in the service consumption. Mandatory cell id identifiers assist the handover decision process and reduce the tuning failure probabilities.

Figure 9 shows the basic soft handover scenario in DVB-H networks.

\section{APPROACHES TO THE Handover Problems in DVB-H}

Handover in DVB-H is a novel research issue. In order to evaluate the existing and the forthcoming handover solutions, a systematic categorization and evaluation method is needed. Two approaches are proposed here. One is to evaluate and categorize the handover algorithms based on the challenges that are introduced by the handover process of DVB-H. The other is to study DVB-H handover from different handover stages' points of view. In this way, it is believed, from the authors' own research experiences, that handover in DVB-H can be systematically studied and evaluated. These two aspects are described in detail in the following two sections.

\section{ChALLENGES IN THE Handover Process of DVB-H}

Some challenges may exist in the handover process of DVB-H such as the Ping Pong effect, "fake signals," excessive power consumption, and packet loss. These are the challenges for DVB-H handover in general and the designed algorithms should cope with them. Also, the network planning has a big affect on handover in DVB-H.

\section{Ping Pong Effect}

Because the signal strength fluctuates in the real physical environment the DVB-H receiver has the possibility of detecting strong signals from other cells even though it is located in the original cell, especially in the transmitter shadow areas, for example, when high buildings are blocking line of sight signal transmissions. In this case, the receiver may have the possibility of repeated handover between different cells, causing a Ping Pong effect [30]. Since frequent handover increases power consumption that is critical for handheld battery powered terminals, reducing the occurrence of the Ping Pong effect is one of the key research areas for handover study in DVB-H. The Ping Pong effect should be reduced to the minimum possible in the handover decision-making stage.

\section{FAKe Signal OCCuRrence}

The DVB-H receiver utilizes PSI/SI signaling and information acquired from the TPS bits to discover what services are available within the found signals. The PSI/SI maps IP streams to transport streams and subsequently transport streams with the different frequencies and cells. The cell identification information (i.e., cell id) is also signaled within the TPS bits of each received signal. By utilizing these two signaling mechanisms, that is, PSI/SI signaling and TPS signaling, the receiver can verify that, with one exception, it always hands over to a valid signal. The exception mentioned above refers to [38], where the concept of "fake signals" is introduced. A "fake signal" is a signal that has the same frequency and cell_id as the 


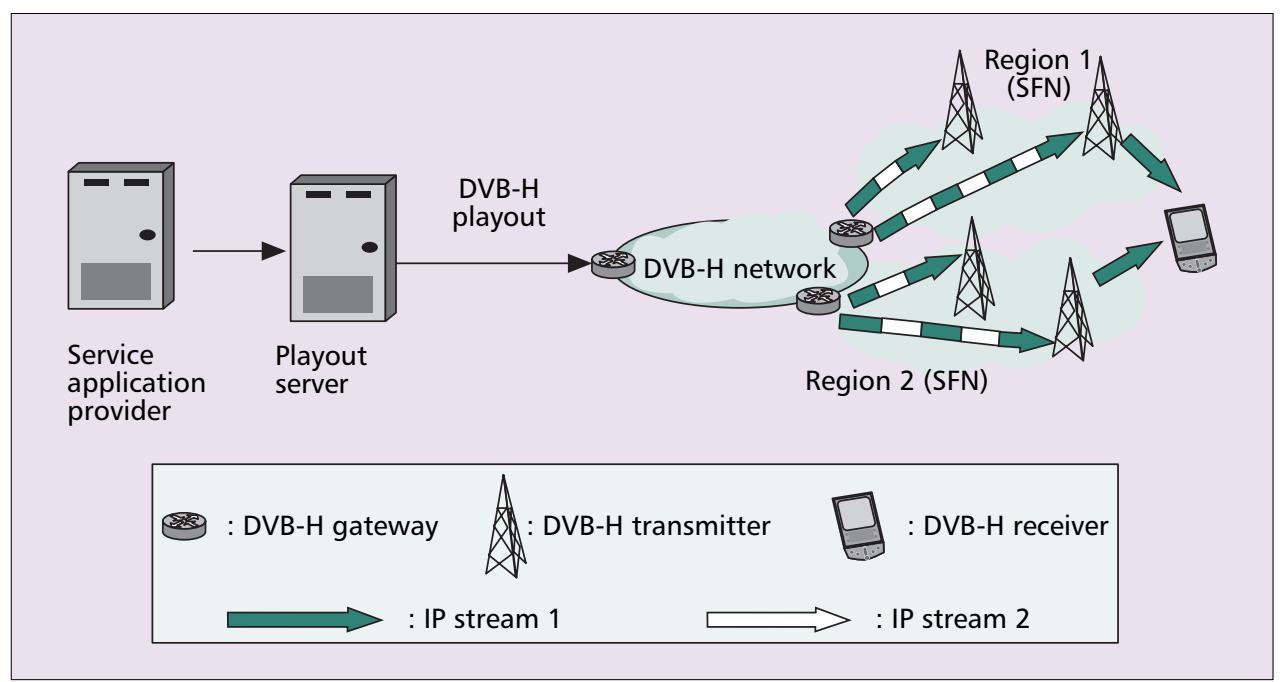

Figure 9. Soft handover illustration.

targeted signal, but which actually is from a different network; hence, it is very unlikely that the receiver is able to receive currently consumed IP streams from it. Such a situation may occur, for example, when a cell of another network is using the same cell id and frequency as the cell that the receiver aims to hand over to, as shown in Fig. 10. The situation described above is possible even though it can be avoided by appropriate network design and co-operation between network operators.

\section{POWER CONSUMPTION}

In addition to the two main possible problems mentioned above in the handover process of DVB-H, power consumption is the most important concern. Power consumption has always been a critical challenge for mobile handheld terminals [52, 53]. In fact, reducing power consumption is the reason why the DVB-H standard was developed [29, 54]. Better handover algorithms in DVB-H can consume less battery power compared with other handover algorithms. Although the introduction of time slicing has reduced the power consumption of DVB-H to a considerable extent compared with that of DVB-

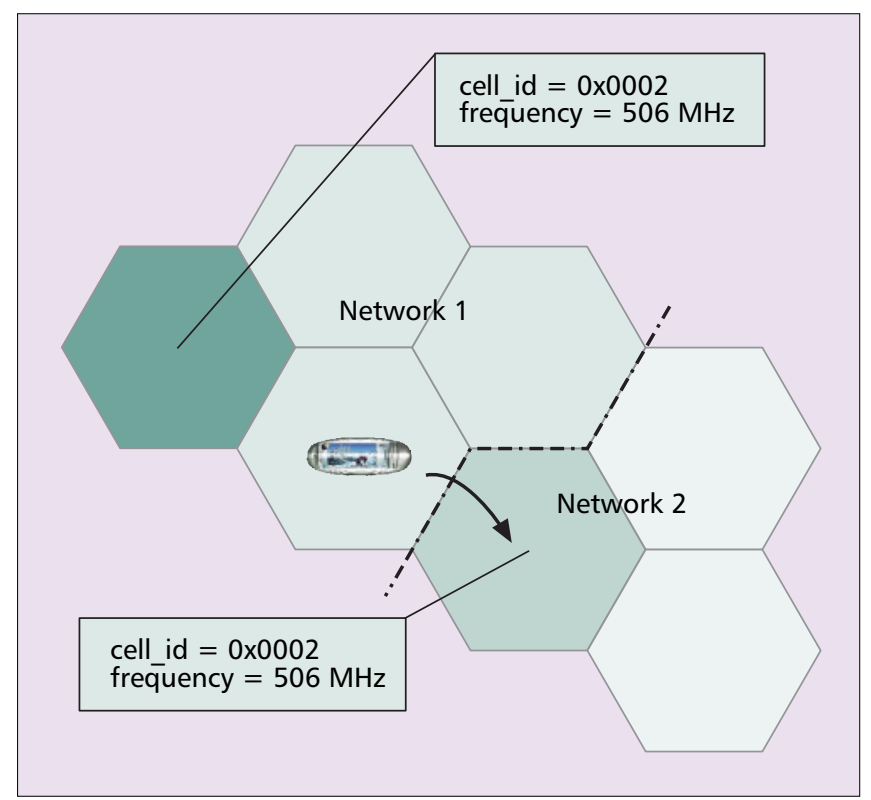

Figure 10. Tuning failure or fake signals.
$\mathrm{T}$, the handover algorithm in DVB-H should be fully exploited to further reduce the power consumption of the terminal in different stages and to avoid unnecessary power consumption as much as possible when handover is present.

\section{PACKet LosS}

DVB-H is a unidirectional broadcasting network. If some packets are lost during the handover process there will be no retransmission of the lost packets. Packet loss will most probably happen when the terminal tries to synchronize to the target frequency and transport stream in the handover process. Delay and jitter are very common in the IP networks that are the service-feeding networks of DVB-H. Since even a single lost packet will have a disastrous effect for some IP Datacast services in DVB-H (e.g., file downloading), strict synchronization techniques must be used in the synchronization of the time sliced services of DVB-H. Further discussion of this issue can be found in [35].

\section{HANDOVER STAGES IN DVB-H}

Handover in DVB-H consists of three stages: handover measurement, handover decision-making based on the handover criteria, and handover execution [55]. All the previous research work on handover in DVB-H can be categorized into or was targeting these three stages.

\section{Handover MeASUREMENT}

Handover measurement is the first of the handover stages. In DVB-H the handover measurement takes place in the off time of the time slicing mode. The terminal will switch off the tuner and the demodulator in the off burst period. However, the front-end receiver has to keep measuring the signal strength from neighboring transmitters in order to monitor the signal strength fluctuation. If the signal strength of the received signal is degraded to some degree, the handover decision-making process will be triggered. The wake up time for the next burst will be signaled in the current burst period. The detailed procedure is given in [42].

\section{HANDOVER DECISION-MAKING BASED ON THE HANDOVER CRITERIA}

In the second stage of the handover process, the DVB-H ter- 


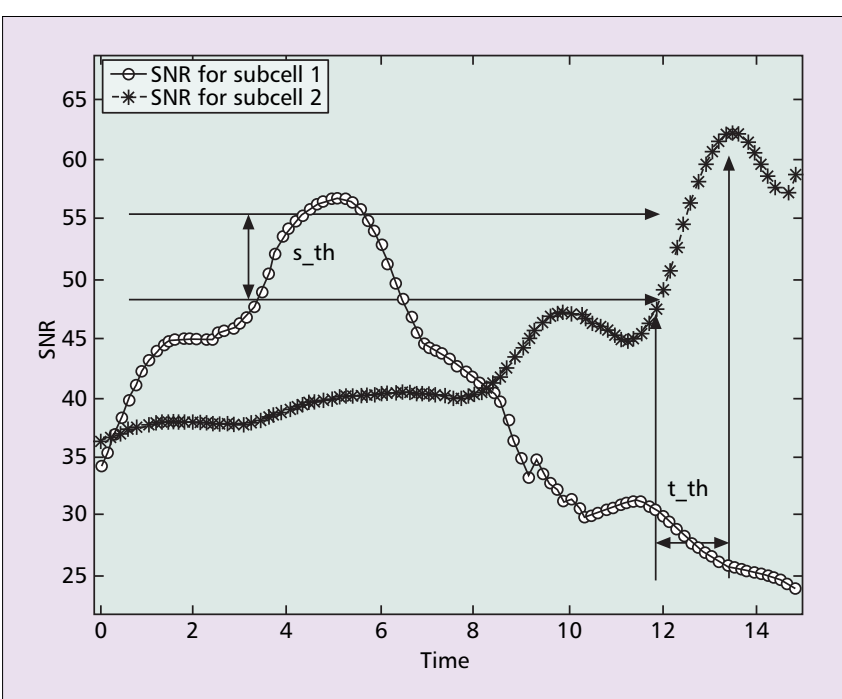

Figure 11. SNR and time threshold for handover decisionmaking.

minal will decide whether it should perform handover based on the predefined handover criteria. The most commonly used handover criteria parameters are the Received Signal Strength Indicator (RSSI) and the Signal Noise Ratio (SNR) $[30,38]$. This survey article only considers MFNs, so the selfinterferences between different transmitters in SFNs will not be considered. When the RSSI or the SNR is identified as degraded to some degree from the handover measurement of the first stage, the handover decision-making process will be triggered. Taking the SNR as the handover criteria for example, once the SNR threshold margin value s_th is reached for a certain threshold time $t$ th, the receiver will tune to the frequency with the strongest SNR value to continue service reception. The SNR and duration threshold are shown in Fig. 11. In addition to the physical layer parameters, it is increasingly important to take the quality of currently received IP streams as one handover criterion especially within a MFN network. This is also recognized in $[48,16]$.

\section{HANDOVER EXECUTION}

Handover execution is the last stage of the handover process. After the terminal has made the handover decision it will perform the handover execution stage. In this stage, the terminal attempts to synchronize to the handover target signal and to continue the reception of the currently received services without interruption. In order to validate whether the handover target signal is the correct one, the DVB-H signaling information contained in the TPS bits and the PSI/SI tables will be utilized.

\section{RESEARCH CONDUCTED ON HANDOVER IN DVB-H}

Handover in DVB-H is a novel issue. However, much research work has already been reported in this area at the time of writing this survey. In this situation, an attempt is made to survey as far as possible the work that has been reported and forecast the work that will be done.

An instantaneous Received Signal Strength Indication (RSSI) value based handover scheme was proposed in [38]. This handover scheme is the first for DVB-H published in the literature. This scheme uses the off burst time to measure the RSSI value. After comparing the current RSSI value with that of adjacent cells, it hands over to the cell with the strongest

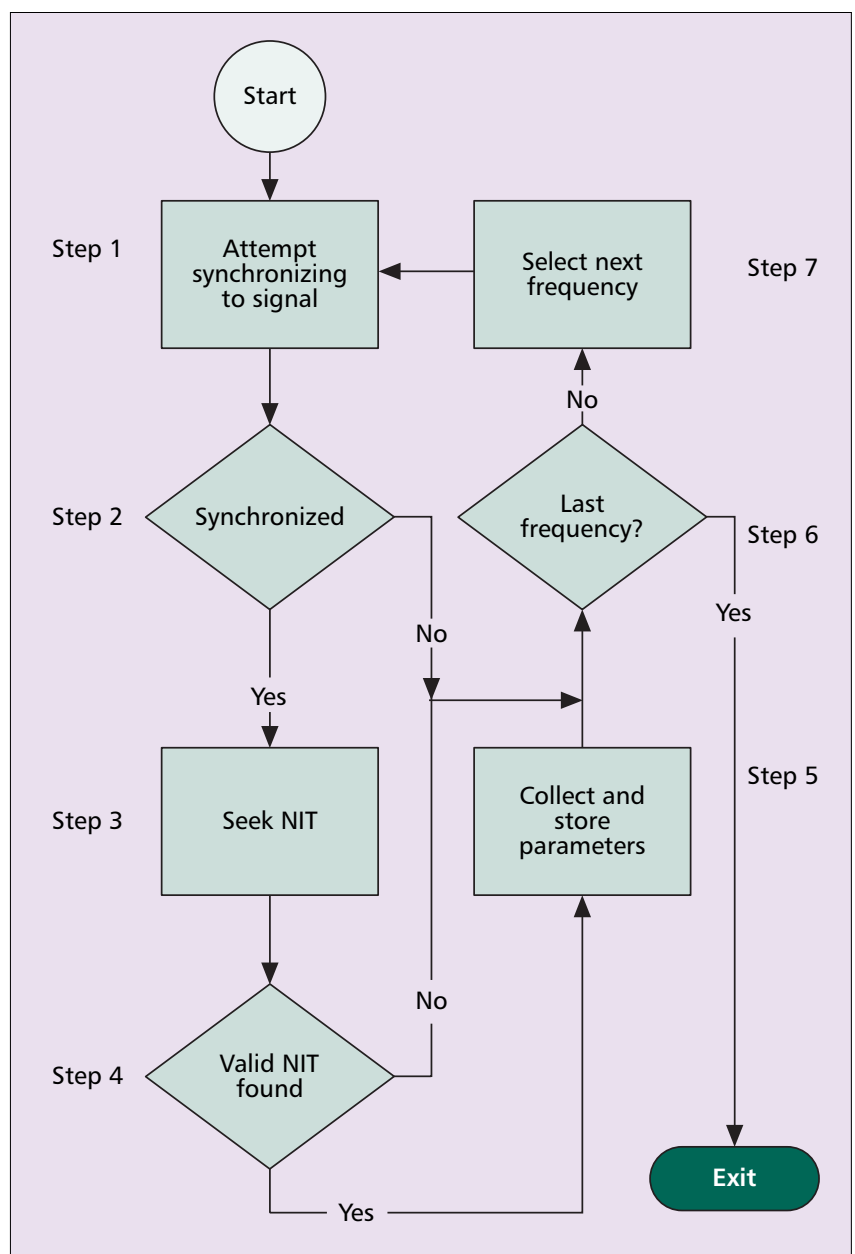

Figure 12. Measurement stage of the handover algorithm according to [38].

RSSI value. The handover stages for this handover algorithm are shown in Figs. 12 and 13. Since the RSSI value can vary due to multipath, interference or other environmental effects it may not give a true indication of the communication performance or the range and mistakenly measuring the RSSI value would result in the Ping Pong effect in handover measurement consuming power unnecessarily. The RSSI value could be measured many off burst times with the RSSI value being measured at least once every off burst time in the worst case. Constant measuring of the adjacent cells signal level without any handover prediction leads to more battery power consumption. In order to overcome these shortcomings, a better handover prediction algorithm had to be developed.

Hamara presented an enhanced version of the algorithm of [38] in his thesis [48] where, in addition to using the RSSI value as a handover criterion, currently consumed services and bit error rate were taken into account. This thesis is the first thesis about DVB-H handover in the literature. It gives an extensive analysis of the handover aspects within DVB-H in the light of the standard solutions at the time.

In [30] another handover scheme based on post-processing of the measured SNR value was proposed to avoid the Ping Pong effect and to get rid of the received "fake signals." In the SNR-based handover scheme, the SNR is calculated from the RSSI and the noise characteristics and provides a more accurate estimate of the received effective signal than the RSSI. The main idea of post-processing the SNR values is to calculate the Cumulative Distribution Functions (CDFs) of all the SNR values. A CDF describes a statistical distribution. It gives at each possible outcome of the received signal SNR the 


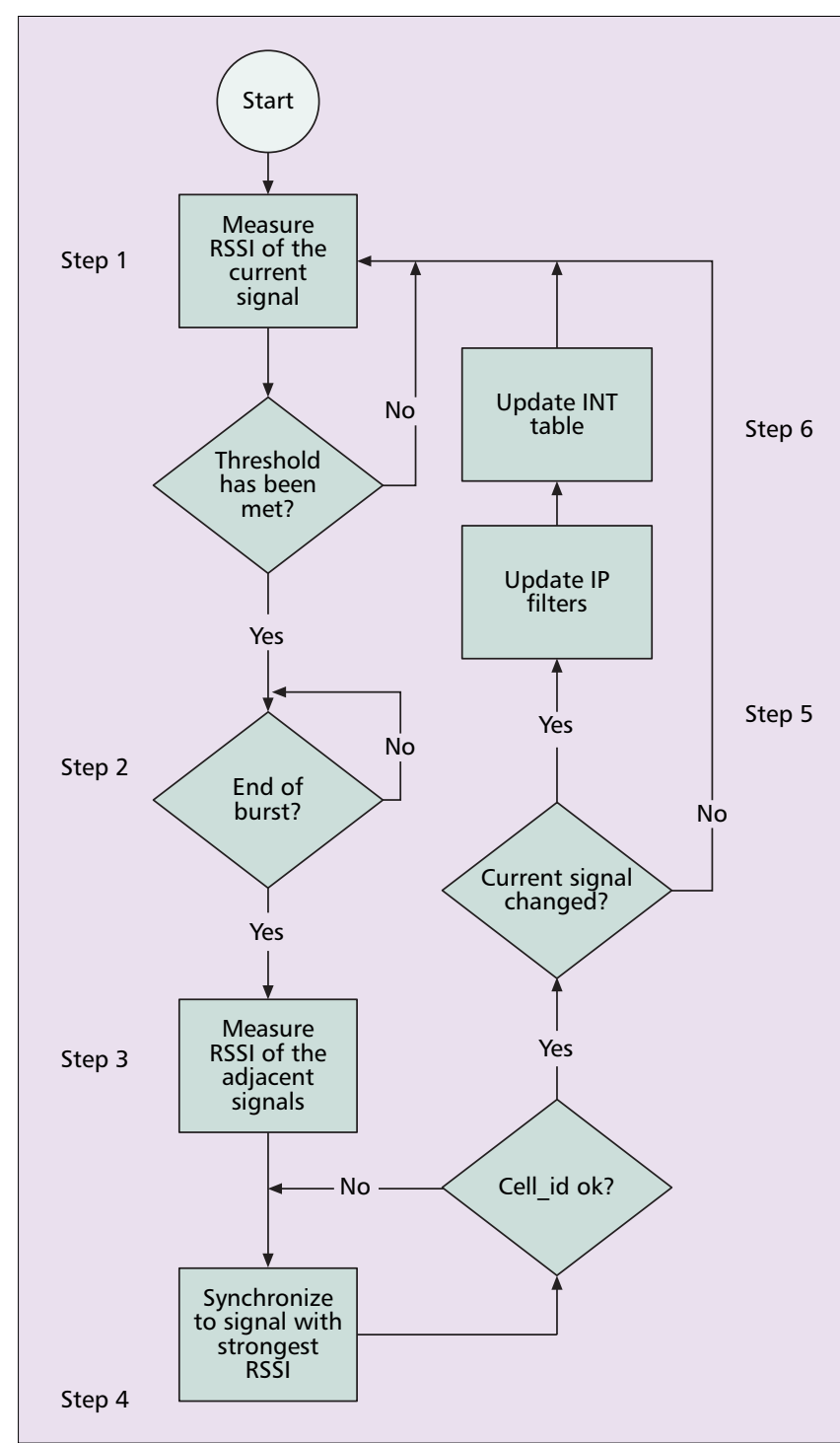

Figure 13. Decision-making and execution stages of the handover algorithm according to [38].

probability of receiving that outcome or a lower one. Because the CDF gives a probability value, its value depends not only on the current SNR value, but also on the SNR history of the signal. This not only eliminates the frequent handover phenomenon seen in instantaneous RSSI value-based handover, but also avoids the "fake signals" caused by frequency confusion. Although simulation has shown the feasibility of this simple algorithm, further studies and field trials need to be done to investigate the limitations of this algorithm.

Vare, Hamara, and Kallio [69] have proposed a new method for signaling cell coverage areas by means of bitmap data to improve the handover performance in DVB-H. A new table called the Cell Description Table (CDT) is proposed for the PSI/SI. By using a CDT, up to 256 different signal levels within the cell coverage area can be signaled to the receiver to inform it of the cell coverage. The terminal can make better handover decisions from the information about the cell coverage area to reduce the Ping Pong effect and "fake signals." However, in this proposed handover scheme more bandwidth and receiver memory consumption is needed to support the CDT information process. In addition, the DVB-H handheld receiver must have GPS support which will be an additional cost to the customer. This kind of cost cannot be neglected, especially in the early DVB-H roll out stage when potential

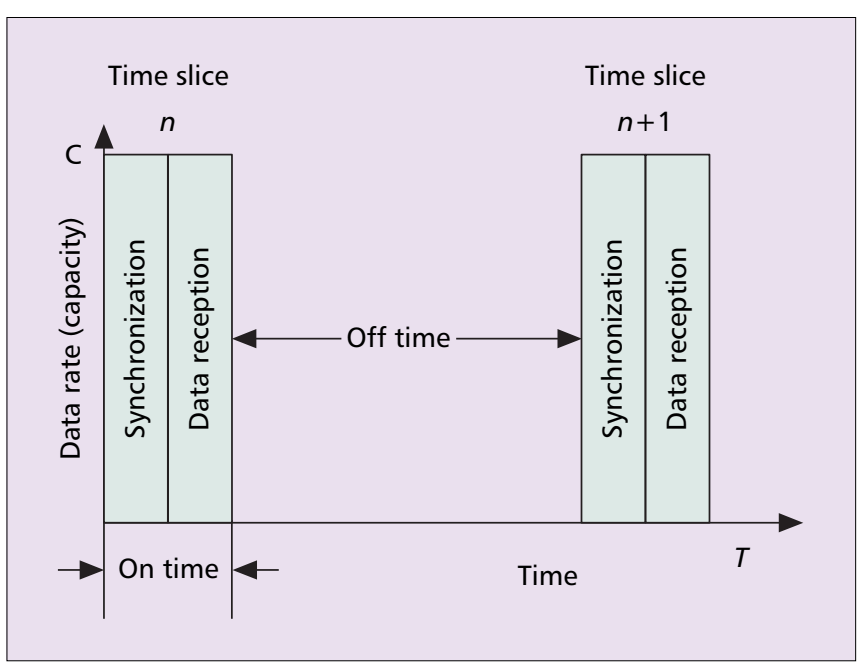

Figure 14. Position of the synchronization duration in the time slicing mode.

customers are still not fully convinced of the benefits of DVB$\mathrm{H}$ services. Transferring the cost from the terminal side to the network side is an alternative solution if the network can provide the same location information to the terminal as a GPS receiver does.

Yang et al. [55] investigated different handover decisionmaking algorithms and proposed a novel hybrid handover decision-making algorithm. The key idea of [55] is to reduce the frequency of handover measurement in the handover decision-making stage by designing a soft handover algorithm with prediction of the handover moment. The proposed handover decision-making algorithms are Context-Aware Handover Decision-making, Location-Aided Handover Decision-making, UMTS Aided Handover Decision-making, Repeater-Aided Handover Decision-making, and Hidden Markov Model Based Decision-making. A comparison of the different handover decision-making algorithms is presented in Table 1 according to [55]. As a conclusion to [55], a hybrid handover decision-making algorithm is proposed that can utilize the advantages of the different handover decision-making algorithms while eliminating the limitations of them by using a central management module to control the choice of one of the different handover modules in different environment scenarios. The feasibility and the limitations of the proposed handover decision-making algorithm need to be validated through field trials.

A more detailed description of different handover algorithms, especially of the different handover decision-making algorithms in dedicated DVB-H networks and in converged DVB-H/UMTS networks, is presented in [57]. The investigation and research of the handover in converged DVB-H and UMTS networks is thought to be one of the first in the literature.

Schwoerer [47, 56] and Vesma [47] target power consumption reduction by utilizing novel synchronization techniques in the handover execution stage of the handover process. The handover execution stage is equal to the signal synchronization, and the on time in the time slicing mode consists of both the synchronization time and the burst data duration time, as shown in Fig. 14; the main idea of $[47,56]$ is to try to minimize the synchronization time to further reduce the power consumption. The main exploitable synchronization time in the synchronization stage is the TPS synchronization, as shown in Fig. 15 [47].

Schwoerer and Vesma [47] proposed a new synchronization technique called correlation-based "Fast Scattered Pilot Synchronization" for DVB-H receivers to substitute the con- 


\begin{tabular}{l|l|l|l} 
Algorithms & $\begin{array}{l}\text { Saved Power Consumption } \\
\text { Compared with RSSI Algorithm }\end{array}$ & Advantages & Disadvantages \\
\hline Context aware & $60 \%$ in the worst case & Simple and efficient & Less robust to environment \\
\hline Location aided & Up to $97 \%$ & Simple and efficient & $\begin{array}{l}\text { Costly and only in motorway } \\
\text { scenario }\end{array}$ \\
\hline UMTS aided & Not determined & $\begin{array}{l}\text { Complex and needs UMTS } \\
\text { network }\end{array}$ \\
\hline Repeater aided & Up to $63.22 \%$ & Simple and efficient & Costly \\
\hline HMM based & Not determined & $\begin{array}{l}\text { Simple, less costly, } \\
\text { efficient }\end{array}$ & $\begin{array}{l}\text { Needs Enough } \\
\text { Measurements Data }\end{array}$
\end{tabular}

Table 1. Comparison between different handover decision-making algorithms according to [55].

ventional TPS-based OFDM frame synchronization for finding the position of Scattered Pilots within an OFDM symbol in the handover execution stage. It exploits the temporally repetitive structure of the scattered pilots and Schwoerer and Vesma [47] showed using mathematical analysis that the synchronization time (until channel estimation) could be cut by 84 percent by using the new technique. Reducing the synchronization time means reducing the power consumption. Therefore, "Fast Scattered Pilot Synchronization" can reduce the power consumption in the DVB-H handover execution stage. Schwoerer [56] proposed another purely power-based "Fast Scattered Pilot Synchronization" method. It uses the fact that scattered pilots are amplitude-boosted by $4 / 3$ to find the current Scattered Pilot Raster Position (SRPR) [43]. It is shown in [56] that 89 percent of the synchronization time can be saved using power-based "Fast Scattered Pilot Synchronization."

In [35] May focused on the handover execution stage of the handover process in DVB-H. Because the IP network delay and jitter may be different for different cells May proposed a technology called "phase shifting" to synchronize the signals of adjacent cells in IP Datacast over DVB-H networks in order to ensure loss-free handovers. When the terminal moves from one cell to another, synchronization techniques must be used to ensure that there is no packet loss caused by a time sliced burst overlap when the next time sliced burst arrives. There are three different possibilities for the types of synchronization. The first is no synchronization that of course will cause considerable packet loss. The second is in-phase synchronization where all the transport streams in different cells must be transmitted in perfect synchronization, that is, at the same universal time. This cannot be ensured without a buffer system in the network side. The third one is "phase shifting" synchronization where there is a time shift between adjacent cells to ensure that there is enough time between the neighboring time slices to avoid the possible packet loss caused by time slice overlap. The phase shifting principal for handover between any two cells as a four-color problem [58] is illustrated in Fig. 16 according to [35]. Analysis and simulation showed that the phase shifting synchronization techniques can achieve much better performance with respect to the packet loss probability compared with the no synchronization and "in phase" synchronization techniques.

The DVB Project technical reports [45] and [16] proposed a simple handover algorithm for handover in DVB-H based on the handover algorithm in DVB-T. The basic idea is for the DVB-H terminal to use the terrestrial_delivery_system_descriptor, the frequency_list descriptor, the original_network_id and the transport_stream_id together as a pair along with the service_list_descriptor to decide which frequency and transport stream the receiver should switch to in the handover process. Several methods to reduce the risk of tuning failures or "fake signals" are also presented. The first one proposed in [45] is called "local SI insertion" which makes each cell a separate network by individual Service Information (SI) insertion. In this case, there will be only one frequency per network. The second method utilizes the cell identifier so the terminal can know which cell it has entered. In this case, the terminal can determine and check the cell id of a signal from its TPS bits to see if it is in its cell id list of interest after checking the frequency thus reducing the tuning failure. The third method uses location data from GPS receivers to aid the handover so the terminal can determine the destination cell reducing tuning failure. The last method in [45] uses two front-ends including a second demultiplexer. In this case, the tuning of different frequencies can be done in parallel and the target cell frequency can be validated in advance so that the risk of tuning failure can be completely eliminated.

\section{DESIGNING A BETTER HANDOVER AlgORITHM FOR DVB-H}

The handover in DVB-H networks is the subject of on-going research and different approaches for designing handover algorithms by utilizing mechanisms defined in $[16,29]$ and in [10] are developed all the time. In this section, some key points are proposed as criteria for designing an efficient handover algorithm in DVB-H networks identified from the research conducted by the authors.

\section{Handover DeCiSION-MAKING StaGE}

One of the key aspects in designing an efficient handover algorithm for DVB-H is to exploit the possibilities of reducing battery power consumption. The handover decision-making stage is the handover phase where the battery power consumption reduction can be fully exploited. The main objective in the handover decision-making stage is to try to predict the handover moment to reduce the number of off burst time intervals that are used for handover measurement.

\section{COMPLEXITY AND COMPATIBILITY}

The design of a handover algorithm for DVB-H should not conflict with the already consolidated DVB-H standards and the complexity of the handover algorithm should be fully exploited to ease the difficulty imposed on the receiver design. 


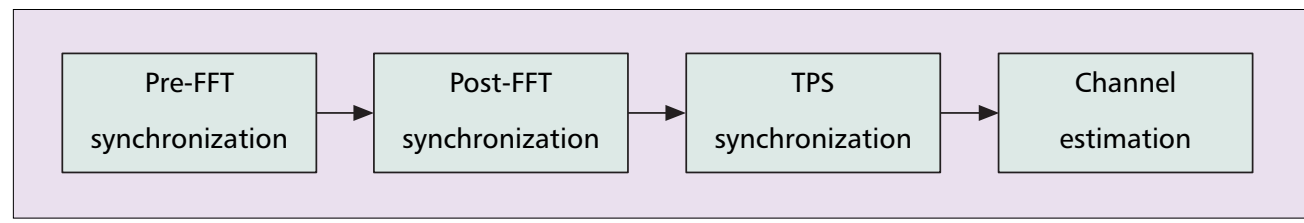

Figure 15. TPS synchronization in the synchronization stages according to [47].

\section{UTILIZATION OF ADDITIONAL SignALING INFORMATION}

Additional signaling information should always be fully exploited by the handover algorithm. Handover in dedicated DVB-H networks has the characteristic of being passive where only the unidirectional transmission from the network to the terminal is possible. If additional signaling information is available, it should be used to help the handover process. Take the converged terminal as an example; converged DVB$\mathrm{H}$ and GPRS/UMTS terminals have the advantage of having an interactive uplink channel. In this case, the uplink channel can be utilized to aid the handover process and this UMTS aided handover is a kind of active handover. The network parameters transmitted from transmitters and repeaters can also be fully utilized by the passive DVB-H receivers to aid the handover process.

\section{AdDITIONAL EQUIPMENT CoST}

DVB-H terminals should be affordable for consumers. An additional attachment such as a GPS receiver can improve handover efficiency but can also increase the terminal price. The authors believe that DVB-H handover algorithms should focus on utilizing existed signaling information available in the DVB-H standard to avoid the extra cost of introducing new network equipment (such as expensive repeaters) or terminal attachments (such as GPS receivers) purely for handover purposes.

In addition, the handover challenges presented earlier should be carefully considered when a handover algorithm is designed. The challenges such as the Ping Pong effect, "fake signals," and power consumption are sometimes related each other. For example, because more Ping Pong effect means more power consumption, when the Ping Pong effect is solved, the power consumption is usually reduced as well.

Different handover algorithms have different characteristics. It is sometimes difficult for one algorithm to be used for all situations, for example, a handover algorithm utilizing UMTS interaction channels will not work when the UMTS network does not exist. While the above-proposed evaluation

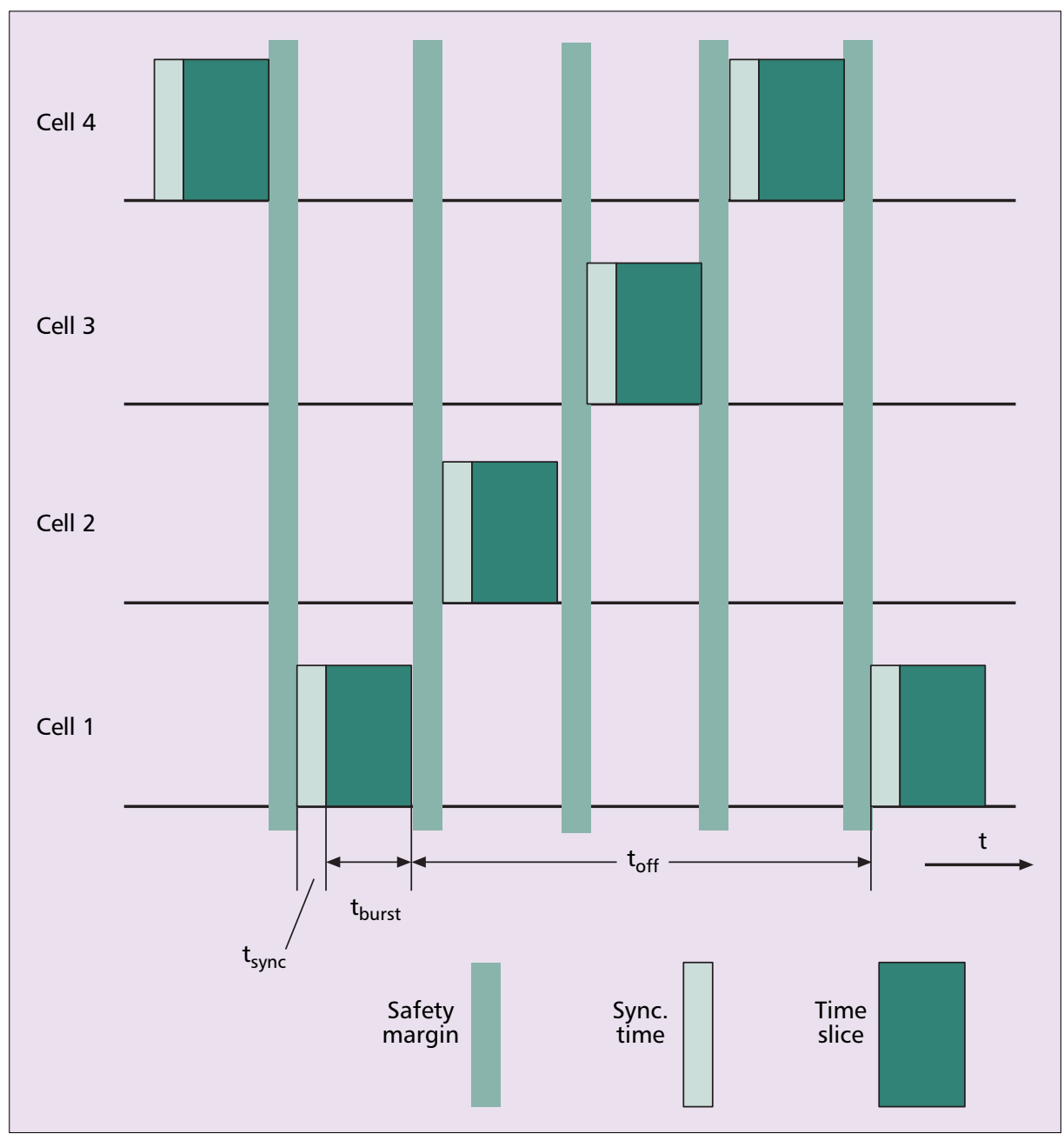

Figure 16. Phase shifting as a four-color problem according to [35] 


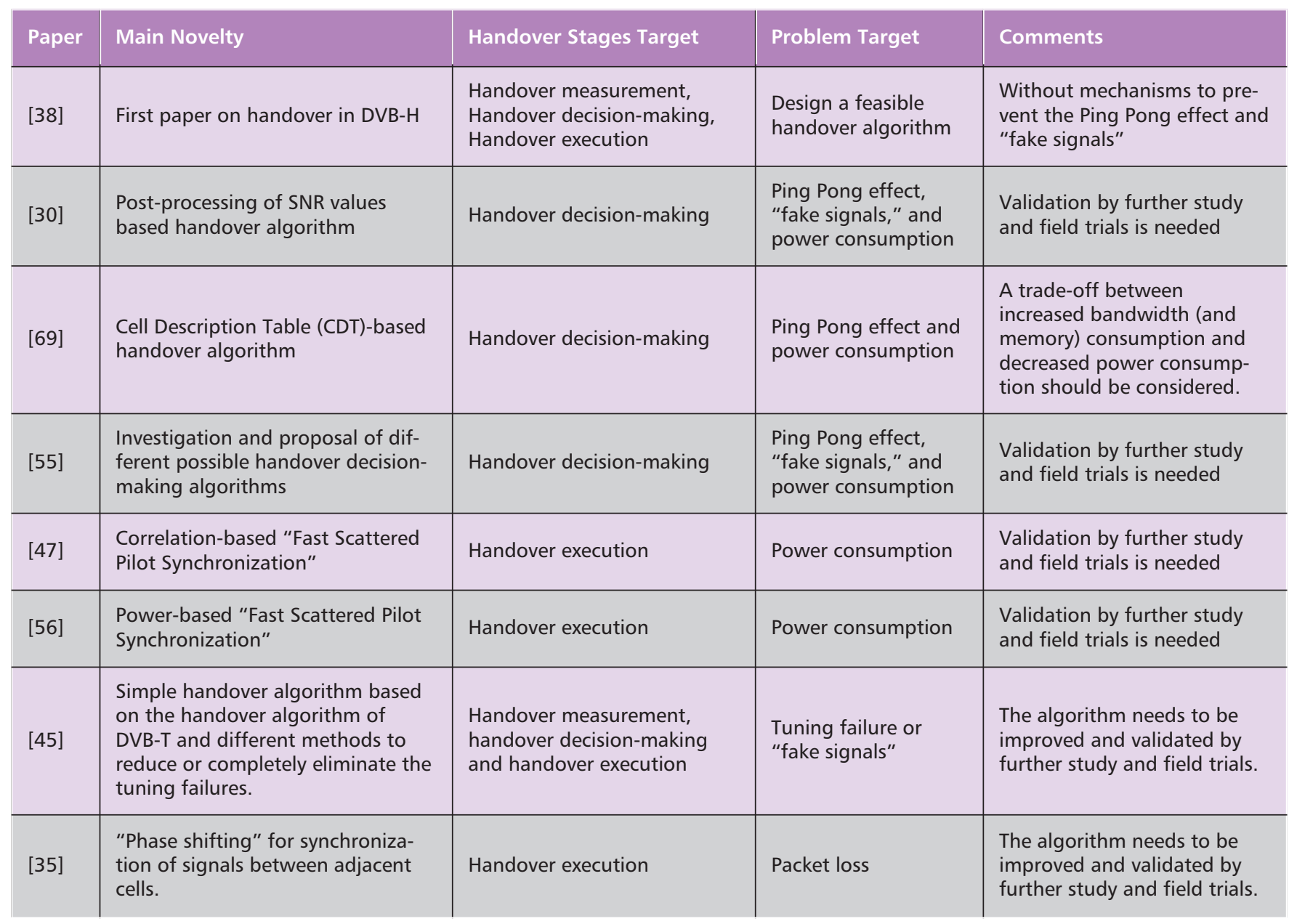

Table 2. Summary of different handover algorithms.

criteria should be considered in designing an efficient handover algorithm for DVB-H, the individual application situation must be taken into account. Designing an efficient algorithm usually implies a trade-off between power consumption, signaling information, and additional equipment cost under the condition that the complexity and compatibility problems are considered.

\section{CONCLUSIONS}

The different handover algorithms for DVB-H presented in the literature have been summarized in Table 2, which shows the different algorithms along with their corresponding handover stages and the problems they are focusing on. It must be noted that new handover algorithms are constantly being developed, so Table 2 may not be exhaustive, as it only relates to the algorithms that were reported at the time of writing of this survey.

\section{Related Projects and Future Work}

A myriad of projects on DVB-H are being carried out around the world. There are two main European research and development projects on DVB-H that have recently been in operation. INSTINCT is the acronym of a European project on IP-based Networks, Services and Terminals for Converging Systems, namely the converged network between Broadcast networks (DVB-T/H) and mobile cellular networks (GPRS/UMTS) [24]. Handover issues were considered by Brunel University, France Telecom R\&D and TDF, in the
INSTINCT project $[24,59]$ which completed its activities in March 2006. WingTV [25] is another European project supported by the European Research and Development program CELTIC [60]. The mission of the WingTV project is to contribute to speeding up the worldwide adoption of the DVB-H standard by validating the technology and providing adequate inputs to forums and standardization bodies. WingTV was planned over five years from 2004 to 2008.

Field trials of DVB-H have already taken place or are in operation in the cities of Helsinki, Berlin, Pittsburgh/USA, Barcelona, Oxford, Metz, and Amsterdam [61-64]. More field trials are taking place and are coming in many other cities around the world. The detailed validation report on the laboratory tests in Berlin and the field trials in Metz is given in the ETSI validation report [65]. All these trials are dealing with Single Frequency Networks; thus, no handover measurements for multifrequency networks have been done. Although there are some other technologies that are competing with DVB-H nowadays, such as T-DMB (Terrestrial Digital Multimedia Broadcasting) and MediaFLO (Media Forward Link Only) $[66,67]$, DVB-H has its unique advantages. Compared with MediaFLO, DVB-H is an open standard thus many more manufacturers support it. Compared with T-DMB, DVB-H has superiority in both technology and cost [68]. For the completion of the DVB-H validation work, the next logical step is the validation of handover that is prerequisite for the multifrequency DVB-H system.

\section{ACKNOWLEDGMENTS}

Dr. Yang and Dr. Owens gratefully acknowledge the support 
for their work that was partly funded by the EU under the IST program as the project INSTINCT (IP-based Networks, Services and Terminals for Converging systems) [24], IST2003-507014. Mr. Väre would like to thank the Kaupallisten ja teknillisten tieteiden tukisäätiö (KAUTE) for supporting his work.

\section{REFERENCES}

[1] U. Reimers, "Digital Video Broadcasting," IEEE Commun. Mag., vol. 36, no. 6, June 1998, pp. 104-10.

[2] U. Reimers, Digital Video Broadcasting, 2nd Edition, Berlin-Heidelberg-New York: Springer, 2004

[3] G. Gardikis, A. Kourtis, and P. Constantinou, "Dynamic Bandwidth Allocation in DVB-T Networks Providing IP Services," IEEE Trans. Broadcasting, vol. 49, no. 3, Sept. 2003, pp. 314-18.

[4] M. Kornfeld, "DVB-H - the Emerging Standard for Mobile Data Communication," IEEE Int'l. Symp. Consumer Electronics, 2004, Sept. 2004, pp. 193-98.

[5] J. Henriksson and P. Talmola, "Coach Potato," IEE Commun. Engineer, vol. 2, no. 4, Aug./Sept. 2004, pp. 28-32.

[6] Digital Video Broadcasting Project, "TV In Hand," DVB-Scene Mag., Mar. 2005, pp. 2-15.

[7] J. Henriksson, "DVB-X," DVB-Scene Magazine, Mar. 2003, p. 7.

[8] Digital Video Broadcasting Project, Sept. 2005, www.dvb.org

[9] www.ipdc-forum.org, Sept. 2005.

[10] DVB Document A079 Rev.1, "IP Datacast over DVB-H: Set of Specifications for Phase 1," Nov. 2005, www.dvb-h-online.org/

[11] DigiTAG, "Television on a Handheld Receiver," Ver. 1.1, 2005, www.digitag.org

[12] www.medialab.sonera.fi/workspace/MBMSWhitePaper.pdf, Sept. 2005.

[13] C. Herrero and P. Vuorimaa, "Delivery of Digital Television to Handheld Devices," Proc. 1st Int'l. Symp. Wireless Commun. Systems, ISWCS 2004, Port Louis, Mauritius, Sept. 2004, pp. 240-44.

[14] 3GPP TS 23.246, “3rd Generation Partnership Project; Technical Specification Group Services and System Aspects; Multimedia Broadcast/Multicast Service (MBMS); Architecture and Functional Description (Release 6)," V6.7.0 (2005-06)

[15] J. Aaltonen, "Content Distribution Using Wireless Broadcast and Multicast Communication Networks," Doctoral Thesis, Tampere University of Technology, Publications 430, 2003.

[16] ETSI, TR 102 377, “Digital Video Broadcasting (DVB); DVB-H Implementation Guidelines," V1.2.1 (2005-11).

[17] www.bbc.co.uk/rd/projects/validate/VALIDATE.pdf, Jan. 2005.

[18] J. Oliver and D. Tymen, "DVB-T and DVB-S to become the Bedfellows of UMTS," IBC2003.

[19] S. O'Leary, D. Priestly, and N. McSparron, "Mobile Broadcasting of DVB-T Signals," IEEE Trans. Broadcasting, vol. 44, no. 3 , Sept. 1998, pp. 346-52.

[20] P. Pogrzeba et al., "Lab \& Field Tests of Mobile Applications of DVB-T," Sept. 2005, www.harris.com

[21] E. Launay, J. Hammerschmidt, and J. Rinne, "Antenna Diversity Techniques for Mobile and Portable DVB-T Receivers," Proc. Int'l. Broadcasting Convention, Sept. 1999, pp. 417-22.

[22] I. Poole, "What Exactly Are... DMB \& DVB-H?," Commun. Engineer, vol. 3, no. 3, June/July 2005, pp. 44-45.

[23] M. Brooks, "Development of Broadcast Technologies for Mobile TV," IEE Seminar on Broadcasting Spectrum: The Issues, Ch. 7, June 2005, p. 3

[24] www.ist-instinct.org, Sept. 2005.

[25] www.celtic-initiative.org/Projects/WING-TV/default.asp, Sept. 2005.

[26] K. Matsumura et al., "A Practical Experiment on Mobile Data Broadcasting," 2005 2nd IEEE Consumer Commun. and Net. Conf., CCNC, Jan. 2005, pp. 337-42.

[27] G. Lee et al., "Development of Terrestrial DMB Transmission System Based on Eureka-147 DAB System," IEEE Trans. Consumer Electronics, vol. 51, no. 1, Feb. 2005, pp. 63-68.

[28] G. P. Pollini, "Trends in Handover Design," IEEE Commun. Mag., vol. 34, no. 3, Mar. 1996, pp. 82-90.

[29] ETSI, EN 302304 “Digital Video Broadcasting (DVB); Trans- mission System for Handheld Terminals (DVB-H)," V1.1.1, (2004-11).

[30] X. D. Yang et al., "Seamless Soft Handover in DVB-H Networks," Proc. Softcom2004, 2004, pp. 27-30.

[31] H. Schulzrinne et al., "RTP: A Transport Protocol for Real-Time Applications," IETF RFC 3550, 2003.

[32] T. Paila et al., "FLUTE: File Delivery over Unidirectional Transport," IETF RFC 3926, 2004.

[33] H. Joki and J. Poikonen, "Analysis and Simulation of DVB-H Link Layer," TUCS Technical Report, no. 695, June 2005.

[34] X. D. Yang et al., "Performance Analysis of Time Slicing in DVB-H," Sympotic 2004, 2004, pp. 183-86.

[35] Gunther May, "Loss-free Handover for IP Datacast over DVBH Networks," IEEE ISCE 2005, Macau, June 2005.

[36] May, G., "The IP Datacast System - Overview and Mobility Aspects," IEEE Int'I. Symp. Consumer Electronics, Sept. 2004, pp. $509-14$

[37] www.digitalradiotech.co.uk/dvb-h_dab_dmb.htm, Sept. 2005.

[38] J. Väre and M. Puputti, "Soft Hañdover in Terrestrial Broadcast Networks," MDM 2004.

[39] ETSI, EN 301 192, “Digital Video Broadcasting (DVB); DVB Specification for Data Broadcasting." V1.4.1 (2004-11)

[40] A. Bria and D.-G. Barquero, "Scalability of DVB-H Deployment on Existing Wireless Infrastructure," Proc. IEEE PIMRC, Sept. 2005, pp. 236-42.

[41] A. Sieber and C. Weck, "What's the Difference Between DVB$\mathrm{H}$ and DAB - in the Mobile Environment?" Technical Review, EBU, July 2004

[42] G. Faria, "DVB-H to Deliver Digital TV to Hand-held Terminals," 2004, www.broadcastpapers.com/BcastAsia04/BAsia04 TeamcastDVBH.pdf

[43] ETSI, EN 300 744, "Digital Video Broadcasting (DVB); Framing Structure, Channel Coding and Modulation for Digital Terrestrial Television." V1.5.1 (2004-11)

[44] ETSI, EN 300 468, "Digital video broadcasting (DVB); Specification for Service Information (SI) in DVB Systems." V1.6.1 (2004-11)

[45] ETSI, TR 101 211, "Digital video broadcasting (DVB); Guidelines on Implementation and Usage of Service Information (SI)," V1.6.1 (2004-05)

[46] DVB Document A079 Rev.1, "IP Datacast over DVB-H: PSI/SI," November 2005, available from www.dvb-h-online.org/

[47] L. Schwoerer and J. Vesma, "Fast Scattered Pilot Synchronization for DVB-T and DVB-H," Proc. 8th Int'I. OFDM Wksp., Hamburg, Germany, Sept. 2003

[48] A. Hamara "Considerations on Loss-Free Handover in IPDC over DVB-H Networks," Master's Thesis, University of Turku, Mar. 2005.

[49] DVB Document A079 Rev.1, "IP Datacast over DVB-H: Electronic Service Guide (ESG)," Nov. 2005, available from www.dvb-h-online.org/

[50] ETSI TS 123009 "Digital Cellular Telecommunications Systems (Phase 2+); Universal Mobile Telecommunications System (UMTS); Handover Procedures," V6.1.0 (2005-06).

[51] DVB Project, "Technical Requirements for IP Datacast," DVB Project White Paper, TM3095R2 (www.dvb.org), 2004.

[52] D. Lenton, "The Small Screen," IEE Review, vol. 49, no. 10, Oct. 2003, pp. $38-41$

[53] S. Hartwig et al., "Mobile Multimedia - Challenges and Opportunities," IEEE Trans. Consumer Electronics, vol. 46, no. 4, Nov. 2000, pp. 1167-78.

[54] J. Aaltonen et al., "Power Saving Considerations in Mobile Datacasting Terminals," Proc. IEEE Int'l. Symp. Consumer Electronics, 2002, pp. F43-F48

[55] X. D. Yang et al., "An Investigation and a Proposal for Handover Decision-making in DVB-H," 14th IST Mobile \& Wireless Commun. Summit, Dresden, Germany, June 2005.

[56] L. Schwoerer, "Fast Pilot Synchronization Schemes for DVB$\mathrm{H}$," Proc. 4th IASTED Int'l. Multi-Conf. Wireless and Optical Commun., Banff, Canada, July 2004

[57] X. Yang, "Handover Issues in DVB-H and in Converged DVBH/UMTS Networks," Doctoral thesis, Brunel University, Jan. 2006.

[58] A. B. Kempe, "On the Geographical Problem of the Four Colors," Amer. J. Math., 1879, pp. 193-200. 
[59] J.-L. Sicre and E. Launay, "Is IP: Multicasting Over DVB-H a Real Business Enabler for a Mobile Telco Operator?," Presentation on Multiradio Multimedia Communication, 2005, Jan. 2005.

[60] www.celtic-initiative.org, Sept. 2005.

[61] M. Kornfeld and U. Reimers, "DVB-H - the Emerging Standard for Mobile Data Communication," EBU Technical Review, Jan. 2005.

[62] www.finishmobiletv.com, Sept. 2005.

[63] www.dutchmobiletv.nl, Sept. 2005.

[64] press.nokia.com/PR/200509/1010115_5.html, Sept. 2005.

[65] ETSI, TR 102 401, “Digital Video Broadcasting (DVB): Transmission to Handheld Terminals (DVB-H); Validation Task Force Report," V1.1.1 (2005-05).

[66] ETSI, TS 102 428, "Digital Audio Broadcasting (DAB); DMB Video Service; User Application Specification," V1.1.1 (200506).

[67] www.qualcomm.com/mediaflo/index.shtml, Sept. 2005.

[68] DVB Document TM3490 DVB-H281r1, "System Comparison: T-DMB vs. DVB-H," 2006, www.dvb-h-online.org/

[69] J. Vare, A. Hamara, and J. Kallio, "Approach for Improving Receiver Performance in Loss-free Handovers in DVB-H Networks," Globecom 2004, vol. 5, 2005, pp. 3326-31.

\section{ADDITIONAL READING}

[1] R. Burow et al., "On the Performance of the DVB-T System in Mobile Environments," Global Telecommunications Conf., IEEE GLOBECOM '98, The Bridge to Global Integration., vol. 4, 8-12, Nov. 1998, pp. 2198-2204.

[2] Z.-W. Zheng et al., "Cutoff Rate and Outage Probability Performance Comparisons Between DVB-T and DMB-T Systems Under Mobile Multipath Channels," IEEE Trans. Broadcasting, vol. 49, no. 4, Dec. 2003, pp. 390-97.

[3] T. Nicolay, M. Buchholz, and M. Gross, "Baseband Signal Processing of Digital Video Broadcasting Direct-conversion Zero-IF Tuners," IEEE Trans. Consumer Electronics, vol. 51, no. 1, Feb. 2005, pp. 48-53.

[4] J. T. Ong et al., "Spatial Variation of Mobile DTV Signals in Singapore," Proc. RF and Microwave Conf., 2004, RFM 2004, Oct. 2004, pp. 28-32.

[5] J. Tavares and A. Navarro, "Optimal IP Packet Length for DVBT Transmission," IEEE ISCE 2005, Macau, June 2005.

[6] Australian Broadcasting Authority, Digital Terrestrial Television Broadcasting Planning Handbook - Including Technical and General Assumptions, Second Edition, The Australian Broadcasting Authority Benjamin Offices, Mar. 2005.

[7] A. Arjona, "Internet Protocol Datacasting - Transparent Interactivity Using Different Communication Channels," Master's Thesis, Helsinki University of Technology, May 2005.
[8] C. Sodergard, "Mobile Television - Technology and User Experiences: Report on the Mobile - TV Project," VTT Technical Research Centre of Finland, 2003.

[9] M. Lattuada et al., "Improving DVB-T Forward Error Correction by Concatenated Turbo Code Scheme," 13th Int'l. Packet Video Wksp. 2003, 2003.

[10] C.-S. Lee, T. Keller, and L. Hanzo, “OFDM-based Turbo-coded Hierarchical and Non-hierarchical Terrestrial Mobile Digital Video Broadcasting," IEEE Trans. Broadcasting, vol. 46, no. 1, Mar. 2000, pp. 1-22.

[11] www.nokia.com/mobiletv

[12] www.udcast.com

[13] www.ebu.ch/en/technical/trev/trev_home.html

[14] dea.brunel.ac.uk/project/Cismundūs/

[15] www.dtg.org.uk

\section{BIOGRAPHIES}

XIAODONG YANG (yang@informatik.uni-goettingen.de) received his B.E. from Tianjin University in 1999, M.E. from Tsinghua University in 2002 both in China and Ph.D. from Brunel University, UK in 2006. Currently, he is a postdoctoral researcher in the informatics institute in Goettingen University in Germany. His research interests are mobility and handover algorithms in broadcast (DVB-T/H, etc), telecommunications (GSM/UMTS, etc.), and IP networks; overlay multicast, HIP, MIPv6, etc. He is a member of IEEE.

JANI VÄRE (Jani.Vare@nokia.com) received an M.Sc. in information technology (telecommunications) from Tampere University of Technology in 2002. He joined Nokia in 2001 where he completed his Master's thesis and worked in the early development phase of the Mobile TV technologies, known today as DVB-H and IPDC over DVB-H. Currently he is working towards his Ph.D. degree (since 2004) in parallel with his daytime work in Nokia. Throughout his Nokia career he has worked on various tasks related to Mobile TV technologies, including standardization work in DVB ad-hoc groups such as TM-CBMS and TM-GBS.

THOMAS J. OWENs (Thomas.Owens@brunel.ac.uk) obtained his $\mathrm{Ph} . \mathrm{D}$. in electrical and electronic engineering from Strathclyde University in 1986. In 1987 he joined Brunel University where he is a Senior Lecturer in the School of Engineering and Design. He is a Chartered Engineer and Chartered Mathematician. He is the author of more than 30 refereed journal papers and book chapters in the areas of engineering and applied mathematics. He is on the Editorial Advisory Board of the International Journal of Engineering Education and the Editorial Board of the International Journal of Services and Standards. He was the project coordinator of the IST FP5 project CONFLUENT and of the IST FP6 Integrated Project INSTINCT. 